Research article

\title{
Evidence for modulation of pericryptal sheath myofibroblasts in rat descending colon by Transforming Growth Factor $\beta$ and Angiotensin II.
}

\author{
Jay R Thiagarajah ${ }^{1}$, Nina M Griffiths ${ }^{2}$, Kevin C Pedley ${ }^{1}$ and \\ Richard J Naftalin*1
}

Address: ${ }^{1}$ Division of Physiology, School of Biomedical Sciences, King's College London, Guys Campus, London, UK and ${ }^{2}$ Institut de Protection et de Sûreté Nucléaire, Fontenay aux Roses, France

E-mail: Jay R Thiagarajah - jaythiagarajah@hotmail.com; Nina M Griffiths - nina.griffiths@ipsn.fr; Kevin C Pedley - K.C.Pedley@massey.ac.nz; Richard J Naftalin* - richard.naftalin@kcl.ac.uk

${ }^{*}$ Corresponding author

Published: 12 February 2002

BMC Gastroenterology 2002, 2:4
Received: 19 November 2001

Accepted: 12 February 2002

This article is available from: http://www.biomedcentral.com/I47I-230X/2/4

(C) 2002 Thiagarajah et al; licensee BioMed Central Ltd. Verbatim copying and redistribution of this article are permitted in any medium for any purpose, provided this notice is preserved along with the article's original URL.

\begin{abstract}
Background: Absorption of water and $\mathrm{Na}^{+}$in descending colonic crypts is dependent on the barrier function of the surrounding myofibroblastic pericryptal sheath. Here the effects of high and low $\mathrm{Na}^{+}$diets and exposure to whole body ionising radiation on the growth and activation of the descending colonic pericryptal myofibroblasts are evaluated. In addition the effect of a postirradiation treatment with the angiotensin converting enzyme inhibitor Captopril was investigated.

Methods: The levels of Angiotensin II type I receptor (ATI), ACE, collagen type IV, transforming growth factor- $\beta$ type I receptor (TGF- $\beta R I$ ), OB cadherin and $\alpha$-smooth muscle actin in both descending colon and caecum were evaluated, using immunocytochemistry and confocal microscopy, in rats fed on high and low $\mathrm{Na}^{+}$diets (LS). These parameters were also determined during 3 months post-irradiation with $8 \mathrm{~Gy}$ from a ${ }^{60} \mathrm{Co}$ source in the presence and absence of the angiotensin converting enzyme inhibitor, Captopril.

Results: Increases in ATI receptor $(135.6 \% \pm 18.3, P<0.001)$; ACE $(70.1 \% \pm 13.1, P<0.001)$; collagen type IV $(49.6 \% \pm 15.3, \mathrm{P}<0.00 \mathrm{I})$; TGF- $\beta$ I receptors $(291.0 \% \pm 26.5, \mathrm{P}<0.00 \mathrm{I})$; OBcadherin $(26.3 \% \pm 13.8, \mathrm{P}<0.05)$ and $\alpha$-smooth muscle actin $(82.5 \% \pm 12.4, \mathrm{P}<0.00 \mathrm{I})$ were observed in the pericryptal myofibroblasts of the descending colon after LS diet. There are also increases in ATI receptor and TGF- $\beta$ I receptor, smooth muscle actin and collagen type IV after irradiation. Captopril reduced all these effects of irradiation on the pericryptal sheath and also decreased the amount of collagen and smooth muscle actin in control rats $(\mathrm{P}<0.00 \mathrm{I})$.

Conclusions: These results demonstrate an activation of descending colonic myofibroblasts to trophic stimuli, or irradiation, which can be attenuated by Captopril, indicative of local trophic control by angiotensin II and TGF- $\beta$ release.
\end{abstract}




\section{Background}

It has become clear that colonic absorptive function depends not only on crypt luminal cells but also on the myofibroblast cells of the surrounding pericryptal sheath. The main difference between the response of myofibroblasts in descending colon pericryptal sheath from other tissues is the significant barrier to diffusion of macromolecules and $\mathrm{NaCl}$ in the colon generated by the fibronexus i.e. the multiple connections between cells and extracellular matrix $[1,2]$.

The development of the barrier function is evident from the layered structure of the myofibroblasts surrounding the crypt as opposed to an open stellate conformation in the deeper layers of the lamina propria [3]. The pericryptal layers are held together by OB-cadherin and E-cadherin and both these intercellular adhesion molecules are required for anchoring to cytoskeletal elements (smooth muscle actin) [4]. The evidence that the sheath acts as a functional barrier to macromolecules like dextran is demonstrated by the accumulation of these macromolecules both in vitro and in vivo in the pericryptal sheaths of rat and murine descending crypts $[5,6]$. We also have recently demonstrated in vivo that a much higher $\mathrm{Na}^{+}$concentration exists within the sheath than in the lamina propria. This indicates that the sheath retards ion equilibration between the space within the sheath and the lamina propria. Unlike the pericryptal sheath, which is not penetrated by capillaries, the lamina propria is directly irrigated by capillary flow [6].

A number of factors have been shown to influence colonic $\mathrm{Na}^{+}$absorption such as low/high $\mathrm{Na}^{+}$diet, circulating aldosterone and ionising radiation exposure. Whilst epithelial cell $\mathrm{Na}$ /K-ATPase activity for example may be markedly altered by such factors the myofibroblasts may also be considered responsive elements.

\section{Low $\mathrm{Na}^{+}(\mathrm{LS})$ diet.}

The distal colon of rat, rabbit and human responds to aldosterone by generating amiloride- or benzamil-sensitive $\mathrm{Na}^{+}$conductance channels [7-11]. The proximal colon differs from the distal colon in that it does not have amiloride-sensitive $\mathrm{Na}^{+}$conductance channels [4]. Instead, electroneutral $\mathrm{NaCI}$ absorption is mainly accomplished by dual $\mathrm{Na}^{+}-\mathrm{H}^{+}$and $\mathrm{Cl}^{-}$bicarbonate exchanges $[7,8,12-$ 16]. The passive permeability to $\mathrm{NaCI}$ and water is higher in the proximal than the distal colon $[12,15]$.

The view that a low $\mathrm{Na}^{+}$(LS) diet or aldosterone affects colonic absorptive function, solely by increasing the expression of the amiloride-sensitive $\mathrm{Na}^{+}$conductance channel $(\mathrm{ENaC})$ and $\left(\mathrm{Na}^{+}-\mathrm{K}^{+}\right.$ATPase, has been questioned [1719]. Findings with mineraloreceptor knockout mice indicate that control of $\mathrm{Na}^{+}$absorption is not achieved by transcriptional control alone [17]. There is, however, some uncertainty about whether or not the early aldosterone effect causes transcriptional upregulation of $\mathrm{ENaC}$ subunits with another recent report suggesting that increased $\mathrm{Na}^{+}$absorption in the distal colon is directly correlated with transcriptional upregulation [20]. Nevertheless, other factors may be involved in colonic $\mathrm{Na}^{+}$and water transport besides the epithelial $\mathrm{Na}^{+}$channels and transporters. In particular the barrier properties of the pericryptal sheath are integral to colonic fluid transport [1] and may play an important role in LS stimulated fluid absorption.

LS diet, hyperaldosteronism, or high levels of angiotensin II increase the amounts of fibrotic tissue in vascular tissue like heart and surrounding arterioles $[21,22]$. This process leads to myocardial hypertrophy and subsequent heart failure. The primary cause of the increased myocardial fibrosis is invasion of the damaged tissue by macrophages and transformation of fibroblasts into myofibroblasts. Under the influence of AT II these cells produce cytokines, transforming growth factor $\beta$, (TGF $\beta)$, endothelin 1, (ET1 ) and connective tissue growth factor, (CTGF) that stimulate the myofibroblasts to generate collagen $[23,24]$. TGF- $\beta$ signalling occurs through its interaction with TGF$\beta$ type 1 and type II receptors. TGF- $\beta$ initially binds to the type II receptor, which then recruits the type 1 receptor into a large receptor complex and initiates a subsequent signalling cascade $[25,26]$. AT II binding to myofibroblasts in heart valves and the adventitia of coronary arteries has been demonstrated with immunolabelling and autoradiography [22]. The coincidence of angiotensin converting enzyme activity and AT-II type 1 receptors has been observed at sites of fibrosis and high-density angiotensin converting enzyme (ACE) antibody binding has also been observed at the site of myocardial infarction after one week. TGF $\beta$ release by myofibroblasts leads to further release of cytokines by the myofibroblasts closing a positive feedback loop. This in turn leads to overproduction of collagen by the stimulated myofibroblasts.

This potentially pathological process can be modified pharmacologically. Either angiotensin converting enzyme inhibitors (ACEI), such as Captopril or Enalapril; or AT II receptor type 1 antagonists ( $\left.\mathrm{AT}_{1} \mathrm{Ra}\right)$, such as Losartan, prevent both the myocardial fibrosis following myocardial infarction, or hypertension and can also induce regression of fibrosis after it has developed [27]. A combination of Losartan and ACEI prevents post-radiation renal fibrosis induced uraemia in rats [28].

A LS diet has already been shown to increase the amounts of E-cadherin, $\beta$-catenin and smooth muscle actin in the pericryptal sheath cells of rat colon, thereby increasing its strength and barrier properties [1]. 


\section{Radiation Fibrosis}

Fibrosis is one of the major late effects of both radiotherapy and accidental radiation exposure. Its major characteristic is the massive over production and deposition of extracellular matrix components. Fibrosis after radiation has been described in numerous tissues including skin [29], lung [30], heart [31], liver [32] and kidney [28]. In the initial phase there is infiltration of inflammatory cells and macrophages, numerous endothelial cells in neocapillaries and an abundance of myofibroblast cells $[3,33,34]$. These 'activated fibroblasts' are thought to be primarily involved in the deposition of extracellular matrix.

In radiation fibrosis, it has been proposed that there is a loss of regulation of myofibroblast proliferation leading to the pathological increase in matrix deposition as a response to chronic long-term activation of these cells. Important factors in the stimulation of the myofibroblasts to produce matrix are various cytokines and growth factors. Several of these including TGF- $\beta$, Platelet derived growth factor (PDGF), Tumour Necrosis factor (TNF- $\alpha$ ), basic fibroblast growth factor (bFGF), Interleukin 1 and 4 (IL-1, IL-4) and Connective tissue growth factor (CTGF) have been found to be dysregulated in fibrotic lesions [35-37]. In particular the key role of TGF- $\beta$ was shown by the finding of fibrosis in multiple organs including liver and kidney in transgenic mice overexpressing TGF- $\beta$ [37]. Ang II, as mentioned previously, has also been shown to play an important role in fibrotic lesions.

Radiation fibrosis in the small intestine has been shown to be associated with large increases in the amounts of TGF- $\beta 1$, TGF- $\beta 2$ and TGF- $\beta 3$ both in epithelial and mesothelial cells [38] Radiation induced fibrosis has shown in other tissues, such as kidney and skin. There is evidence that myofibroblasts play a major role in this long term effect of radiation [33]. In Crohn's disease there are marked increases in collagen type III and RNA transcripts for procollagens I, III and IV [39].

\section{ACE inhibitors}

Angiotensin converting enzyme inhibitors (ACEI) have been shown to be effective against radiation-induced fibrosis in the lung, heart and kidney. Originally ACEI, such as Captopril and Lisinopril were shown to be effective in reducing structural changes in the heart in hypertension [40]. In radiation-induced fibrosis in the lung, Captopril was effective in preventing pulmonary endothelial dysfunction and was also shown to reduce the accumulation of collagen in the lung interstitium [41]. ACEI were similarly found to ameliorate fibrosis in the heart [42], as well as other indices, such as capillary function and the increase in mast cells. It was shown both in the lung and the kidney that radiation causes an increase in myofibroblasts and that ACE inhibition prevented the proliferation of these cells $[28,43]$. The mechanism of action of ACEI was clarified by studies on lung radiation injury in which the AT II receptor blocker, Losartan was shown to be as effective as ACE inhibition on reducing collagen synthesis [44].

In this paper we demonstrate that a LS diet and radiation damage increase the amounts of angiotensin converting enzyme, AT II type 1 receptors, TGF- $\beta$ type 1 receptor, collagen IV and OB cadherin in the pericryptal sheaths of descending colon and that the radiation induced effects can be prevented by the ACEI, Captopril.

\section{Materials and Methods Confocal microscopy}

The tissue was viewed using a Nikon Diaphot inverted microscope with Nikon Fluor $20 \times$ and $60 \times$ lenses. The microscope was attached to an MRC 600 confocal scanhead, equipped with two detection channels and an $\mathrm{Ar} / \mathrm{Kr}$ mixed gas laser allowing excitation at $488 \mathrm{~nm}$ and 568 $\mathrm{nm}$. Z-axis movement, with $0.1 \mu \mathrm{m}$ resolution, was provided by software controlled stepper motor attached to the fine focus control.

\section{Low and High $\mathrm{Na}^{+}$diet}

In order to vary blood aldosterone levels, rats were fed on LS and HS diets that are known to increase and decrease respectively circulating aldosterone levels. The rats fed on a LS diet received plain flour $+5 \%$ wheat bran with water ad libitum for 10 days. Rats fed on a HS diet received the flour and bran diet, as above, but isotonic saline was substituted for drinking water. The rats maintained a normal weight gain during this period. The effects of the diets on the circulating aldosterone were tested to determine whether they conformed to previously demonstrated effects. Blood samples were obtained from portal venous blood immediately after cervical dislocation.

The normal level of circulating aldosterone in Wistar rats is $1500 \pm 250 \mathrm{pM}$. The effect of the HS diet was to reduce the aldosterone level to $805 \pm 73 \mathrm{pM}(\mathrm{n}=3)$ while the LS diet raised the plasma aldosterone level to $3065 \pm 573 \mathrm{pM}$ $(\mathrm{n}=3)$, which was significantly different from the level seen with the HS diet $(\mathrm{P}<0.01$, Students t-test). These concentrations are within the range of those previously observed with these dietary regimens. $[1,45,46]$.

\section{Irradiation procedure}

Experiments were performed on male Wistar rats (315$360 \mathrm{~g}$ ) obtained from CERJ (LeGenest St Isle France) which were housed, four per cage and kept under constant temperature $\left(21^{\circ} \mathrm{C}\right)$ with a $12: 12$ light: dark cycle. They had free access to food (normal rat chow, 105UAR, France) and water throughout the experimental period. 
During irradiation, rats were conscious and restrained in a ventilated plexiglass tube placed perpendicular to the beam axis and then turned on the horizontal axis to receive homogenous whole body irradiation. Animals were irradiated once using a ${ }^{60} \mathrm{Co}$ source at a dose of $8 \mathrm{~Gy}$ with a dose rate of $0.75 \mathrm{~Gy} / \mathrm{min}$. Control animals were treated in exactly the same manner but not exposed to the source (sham-irradiation) and all were treated at the same time of day.

\section{Captopril treatment}

Four experimental groups were included in the study; Control rats, rats treated with Captopril, irradiated rats and irradiated and Captopril treated rats. Treated rats were given Captopril $(125 \mathrm{mg} / \mathrm{kg}) /$ day $)$ in their drinking water. Tissue for immunocytochemistry was collected as before and data analysis performed also as before.

\section{Tissue preparation}

For high/low $\mathrm{Na}^{+}$experiments rats (Wistar) weighing 150-200 G were killed by cervical dislocation and the descending colon and caecum were removed rapidly and the contents removed by washing with buffer. Colonic mucosa was stripped of its muscle layer and fixed in $2 \%$ paraformaldehyde in PBS at $37^{\circ} \mathrm{C}$ for 30 mins. The tissue was washed and stored in PBS at $4^{\circ} \mathrm{C}$.

For the radiation experiments animals were killed by cervical dislocation at several time points $(1,2$ and 3 months) after exposure to sham and radiation sources. The distal colon was removed rapidly and the contents removed by washing with buffer. Colonic mucosa was stripped of its muscle layer and fixed in $2 \%$ paraformaldehyde in PBS at $37^{\circ} \mathrm{C}$ for 30 mins. The tissue was washed and stored in PBS at $4^{\circ}$.

\section{Immunocytochemistry}

Colonic mucosal tissue $\left(0.5 \mathrm{~cm}^{2}\right.$ pieces $)$ was placed in 1.5 $\mathrm{ml}$ Eppendorf tubes. The tissue was then stained according to the following protocol. The procedure was the same for all antibodies used. The tissue was permeabilised in $0.2 \%$ Triton X-100 in PBS for 30 mins. Samples were washed twice in PBS and incubated in blocking buffer ( $2 \%$ goat serum in PBS or 5\% FCS) for 30 mins. The tissue was then incubated for 60 mins with primary antibody (1:100), washed $3 \times$ in blocking buffer and then incubated for 60 mins in each secondary antibody $(1: 100)$ and left in blocking buffer.

\section{Antibodies}

The antibodies were obtained from the following agencies: Chemicon: rabbit anti-AT II Type I receptor; mouse anti-angiotensin converting enzyme (ACE) - monoclonal, RDI rabbit anti-collagen Type IV; Santa Cruz: goat anti-OB cadherin (C-16), rabbit anti-TGF- $\beta$ Type I recep- tor (R-20). For AT-1, TGF- $\beta$ R1 and collagen IV stained tissue, biotin anti-rabbit IgG was used as the secondary antibody followed by Alexa- 488 NeutrAvidin. For OBcadherin, biotin anti-goat IgG was used in combination with Alexa-488 NeutrAvidin and for ACE staining Texas Red goat anti-mouse IgG. All secondary antibodies and Alexa-488 were obtained from Molecular Probes, Eugene Oregon.

\section{Confocal images}

Each piece of tissue was viewed under the confocal microscope using a Nikon 60×/1.4 na Plan Apochromat oil immersion lens. The tissue was viewed from the mucosal side. The focus plane was taken to the surface of the tissue and images were captured at $10 \mu \mathrm{m}$ steps down using the automatic Z-step motor. Images were taken from $0 \mu \mathrm{m}$ down to $40 \mu \mathrm{m}$ below the surface. The images that were captured represented as much as possible the general level of staining throughout the whole tissue and were captured with the same optical conditions, gain and section size.

\section{Image analysis}

The captured images were analysed using the program NIH image (Wayne Rasband, National Institutes of Health, USA) to quantify the fluorescence from each antibody. The fluorescence was quantified by using the measure function in the program to give the mean grey level of a designated area. The areas were divided into either crypt or intercrypt and were taken by selecting a region of interest within the relevant part of the image. Three areas of both crypt and intercrypt were taken per image and therefore there were thirty measurements per tissue at the various depths. Also one area per image was taken as a background value. The mean and SEM of the measurements after background subtraction from each image was calculated. The average and SEM of the numbers at depths of $20 \mu \mathrm{m}$ and $30 \mu \mathrm{m}$ were calculated and plotted. The histograms were calculated after subtracting backgrounds from conjugate controls with no first antibodies present. Images at 0,10 and $40 \mu \mathrm{m}$ were not analysed usually because the images close to the surface tend to show heterogeneous antibody staining and those below $40 \mu \mathrm{m}$ tend to become blurred.

\section{Statistics}

Estimates of statistical significance were obtained using Student's t tests for paired data and one-way analysis of variance (ANOVA).

All experiments concerning radiation were conducted according to the French regulations for animal experimentation. Ministry of Agriculture Act No 87-848,19 October 1987 and all experiments on high and low $\mathrm{Na}^{+}$diets were carried out under Home Office Regulations in a fully su- 

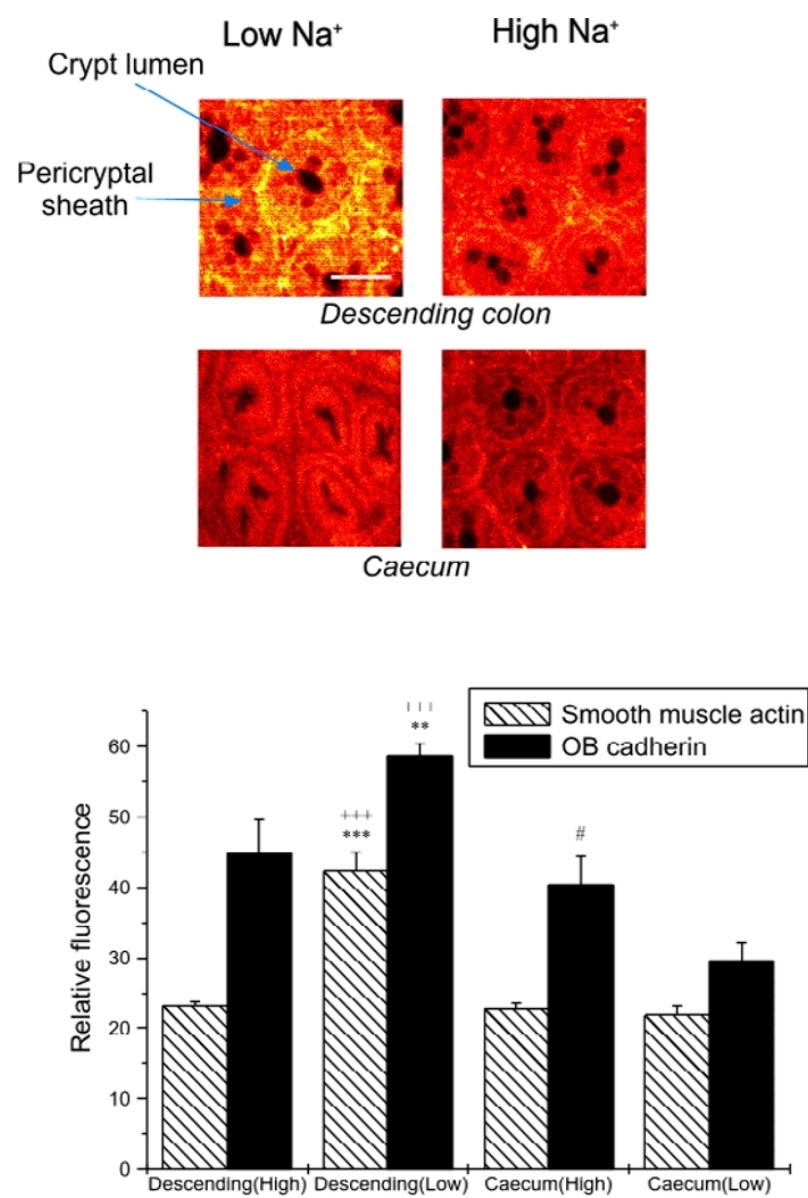

Figure $1 \alpha$-smooth muscle actin and OB cadherin levels in descending colon and caecum of rats fed on high and low $\mathrm{Na}+$ diets. Confocal images show $\alpha$-smooth muscle actin taken at depth of $20 \mu \mathrm{m}$ from surface. Scale bar $50 \mu m$. Graph shows mean fluorescence ( $n=3$ animals) for $\alpha$-smooth muscle actin (stripes) and OB cadherin (black) in the intercryptal space.

Data analysed by ANOVA and Tukey-Kramer multiple comparison tests. ; +- Descending (low) vs Descending (high) *- Descending (low) vs Caecum (low) \#- Caecum (low) vs Caecum (high)

Figure I

pervised conditions within the animal house of King's College.

\section{Results}

Effects of LS and HS diet on $\alpha$-smooth muscle actin and $O B$ cadherin antibody distribution in rat distal colon and caecum.

LS diet increases the amounts of OB cadherin $(26.3 \% \pm$ $12.4)$, and smooth muscle actin $(82.5 \% \pm 13.8)$ in the myofibroblasts of the pericryptal sheath of descending colon in comparison with the amounts found in HS dieted rats ( $p<0.05$ and 0.001 respectively). There is no evidence of any increase in either $\mathrm{OB}$ cadherin or smooth muscle actin in caecal pericryptal sheath cells (Figure 1).
Additionally, there is very little staining for both of these myofibroblast specific antigens in the caecum. These findings confirm our previous finding that there is no significant presence of a pericryptal barrier in caecum and that this is unaffected by dietary $\mathrm{Na}^{+}$intake [1].

Effects of LS and HS diet on AT-II receptor distribution, $A C E, T G F-\beta R I$ and collagen IV distribution in rat distal coIon and caecum.

Development of high density ACE, increases in AT II receptor and TGF- $\beta$ receptor density and increased rates of synthesis by collagen are signs of activation of myofibroblasts [21]. LS diet increases the density of ACE $(70.1 \% \pm$ $13.1)$, AT-II receptor density $(135.6 \% \pm 18.3)$, TGF- $\beta$ receptor density $(291.0 \% \pm 26.5)$ and collagen IV (49.6\% \pm $15.3)$ in the descending crypts of rat in comparison with HS diet ( $p<0.001$ in all cases, (Figures 2 and 3). ACE, ATII receptor and collagen are all more abundant in descending colon than in caecum, both in HS and LS diet conditions $(\mathrm{p}<0.01)$.

No evidence of systematic increases in ACE, AT-II receptor and collagen is found in rat caecal crypts with LS diet. More AT-II receptor and ACE are present in caecal crypts from HS diet than in caecal crypts from LS diet $(\mathrm{p}<0.05)$. However, no difference between high and LS dieted rats is found in the amount of collagen in caecal crypts. We therefore conclude that there is no evidence of activation of caecal myofibroblasts following a LS diet.

There are significant amounts of TGF- $\beta$ receptor in the caecum, which are increased after LS diet $(\mathrm{p}<0.001)$. However, these TGF- $\beta$ receptors may be associated with capillaries as there is much more extensive blood supply in the caecum as compared to the descending colon [47]. We have observed that large proportion of the TGF- $\beta$ receptor staining in the caecum is co-localised with the vascular adhesion molecule PECAM-1 (data not shown). This indicates that unlike in the descending colon, the increases in caecal TGF- $\beta$ RI are largely associated with capillaries and not with myofibroblasts. Recently it has been suggested that microvascular damage initiates gastrointestinal damage by chemotherapy or radiation [48]. The results here suggest that increased expression of TGF- $\beta$ receptor on capillary endothelial cells may restore endothelial function, at least in colon.

\section{Effects of radiation and effect of ACEI treatment on growth of myofibroblasts and the pericryptal sheath.} General observations

During the acute radiation response (days 1-7) food intake was reduced most markedly from days 2-5 with a nadir (60\% reduction) between days 2 and 3 . After one week irradiated animals ate as the controls. Captopril treatment had no effect on food intake. Similarly, during this period 
Low $\mathrm{Na}^{+}$

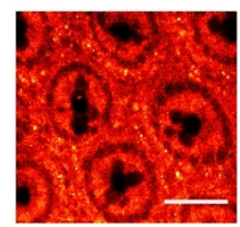

Descending colon

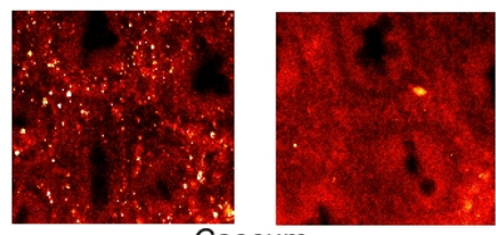

Caecum

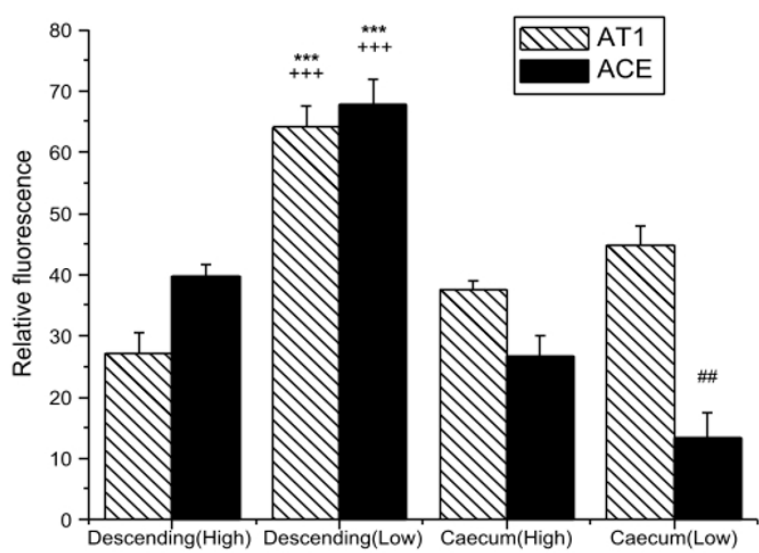

Figure 2 AT 1 receptor and ACE levels in descending colon and caecum of rats fed on high and low $\mathrm{Na}+$ diets. Confocal images show AT 1 receptor taken at depth of $20 \mu \mathrm{m}$ from surface. Scale bar $50 \mu \mathrm{m}$. Graph shows mean fluorescence ( $n=3$ animals) for $A T 1$ receptor (stripes) and ACE (black) in the intercryptal space.

Data analysed by ANOVA and Tukey-Kramer multiple comparison tests. ; +- Descending (low) vs Descending (high) *- Descending (low) vs Caecum (low) \#- Caecum (low)I vs Caecum (high)

Figure 2

animals lost weight and after one week were some 10\% lighter than the respective controls. There was no apparent effect of Captopril treatment on weight loss. At 1, 2 and 3 months post-exposure, irrespective of treatment, irradiated animals never regained the same weight as controls and weighed some $20 \%$ less at 3 months. In both the vehicle- and Captopril-treated groups, circulating lymphocytes remained lower for up to 2 months postirradiation, whereas platelets returned to normal within 1 month. This is in agreement with Moulder and Fish who showed that Captopril did not prevent acute Gl radiationinduced damage [49].
Low $\mathrm{Na}^{+} \quad \mathrm{High} \mathrm{Na}^{+}$
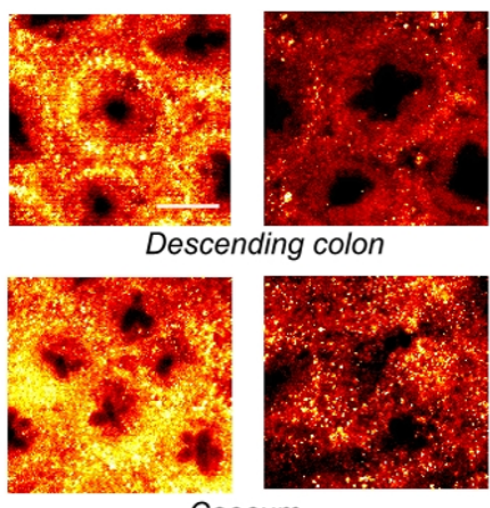

Caecum

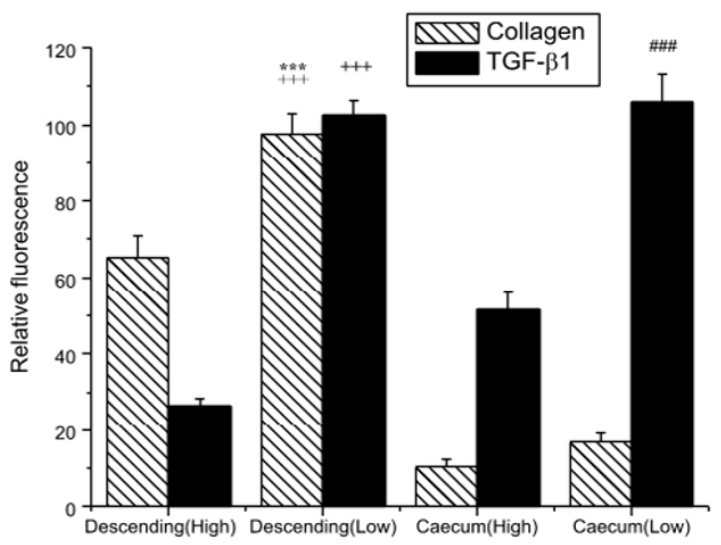

Figure 3 Collagen type IV and TGF- $\beta$ receptor levels in descending colon and caecum of rats fed on high and low $\mathrm{Na}+$ diets. Confocal images show TGF- $\beta$ receptor taken at depth of $20 \mu \mathrm{m}$ from surface. Scale bar $50 \mu m$. Graph shows mean fluorescence ( $n=3$ animals) for collagen IV (stripes) and TGF- $\beta$ receptor (black) in the intercryptal space. Data analysed by ANOVA and Tukey-Kramer multiple comparison tests. ; +- Descending (low) vs Descending (high) *-Descending (low) vs Caecum (low) \#- Caecum (low) vs Caecum (high)

\section{Figure 3}

One month post-irradiation there is a significant increase in the amount of TGF- $\beta$ type 1 receptor in the descending colon pericryptal sheath (Figure 4). This continues to two months suggesting initial and continuing activation of the pericryptal myofibroblasts. By 90 days, there is no significant increase above control in TGF- $\beta$ receptor in irradiated tissues. Further evidence for myofibroblast activation is shown by the increases in $\alpha$-smooth muscle actin particularly in the 30-60 day period post-irradiation (Figure 5).

Previous work has shown [50] that there is a rapid recovery of collagen IV associated with the pericryptal sheath after exposure to whole body ionising radiation. At day 4 , compared with control only $20 \%$ of the collagen IV is present in the pericryptal sheaths of irradiated rats. By day 


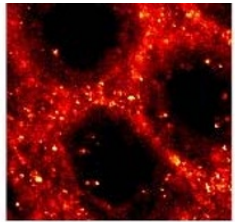

Control

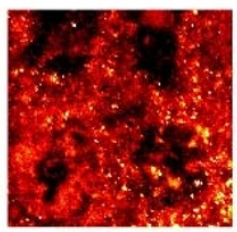

Irradiated

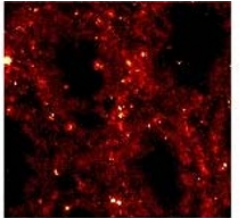

Captopril

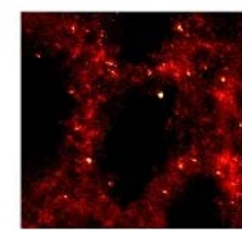

Irradiated + Captopril

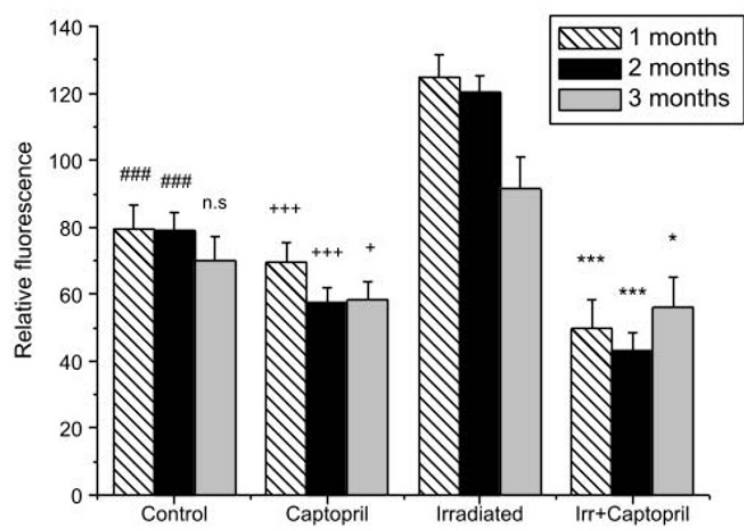

Figure 4 TGF- $\beta$ type 1 receptor in the pericryptal space of rat descending colon after irradiation (8Gy) and captopril treatment at 1,2 and 3 months. Data shown as mean fluorescence ( $n=3$ animals). Data analysed by ANOVA and Tukey-Kramer multiple comparison tests. All comparisons are to irradiated group; \#-Control vs Irradiated, +- Captopril vs Irradiated, *- Irradiated + Captopril vs Irradiated.

Figure 4

10 , collagen IV levels in irradiated colon have fully recovered. During the next 3 months there is an increase in the amount of collagen IV in the pericryptal sheaths of irradiated animals that is not significantly above control until 3 months post-irradiation. This supports the view that increased activity of pericryptal myofibroblasts leads to increased deposition of collagen. Additionally, the increase in TGF- $\beta$ type I receptor one month post-irradiation is consistent with a TGF- $\beta$ mediated activation process.

The increases in collagen, smooth muscle actin and TGF$\beta$ receptor are all abolished by treatment of the animals with Captopril, particularly at two months post-irradiation. Captopril on its own also caused a reduction in smooth muscle actin and TGF- $\beta$ receptor suggesting a down-regulation of the myofibroblasts in control tissue (Figure 6).

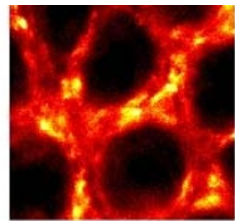

Control

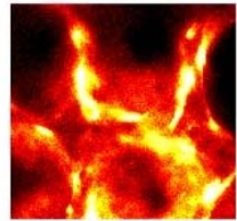

Irradiated

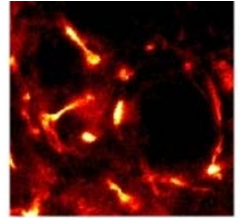

Captopril

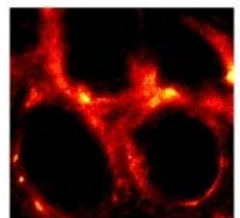

Irradiated + Captopril

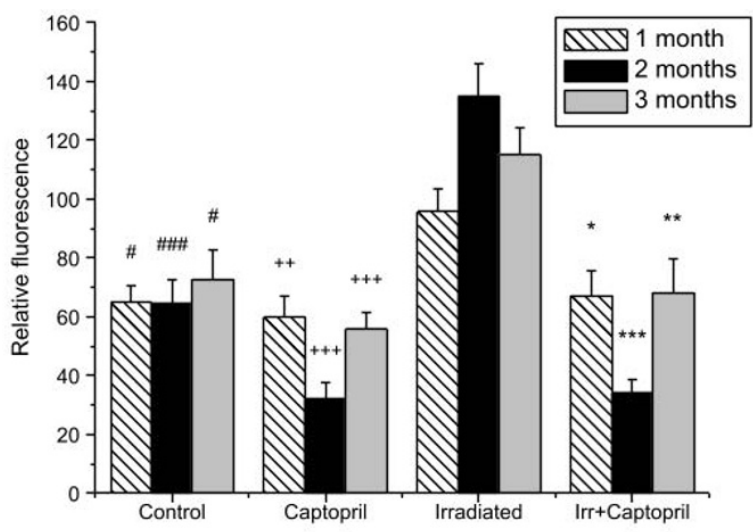

Figure 5 a-smooth muscle actin in the pericryptal space of rat descending colon after irradiation(8Gy) and captopril treatment at 1,2 and 3 months. Data shown as mean fluorescence ( $n=3$ animals). Data analysed by ANOVA and Tukey-Kramer multiple comparison tests. All comparisons are to irradiated group; \#- Control vs Irradiated, +- Captopril vs Irradiated, *- Irradiated + Captopril vs Irradiated.

\section{Figure 5}

\section{Discussion}

Upregulation of AT-II and TGF- $\beta$ receptors in descending colonic mucosa: effects of $L S$ and $H S$ diet.

The presence of AT II type 1 receptors has been shown to be a key factor in development of fibrosis in tissues like heart, liver, lungs, kidney [27-32] and now in colon. Without these receptors it is unlikely that myofibroblast activation or its sequelae, namely increased ACE density at the membrane surface and increased synthesis of collagen by the cells, can occur. Collagen production requires the myofibroblasts to be synergistically activated by AT II and other growth factors, namely TGF- $\beta$ and CTGF $[25,27]$.

To date no barrier function has been ascribed to the enhanced myofibroblast growth surrounding the capillaries in heart, lung, liver or kidney; although this may well be an important factor in the developing dysfunction of 


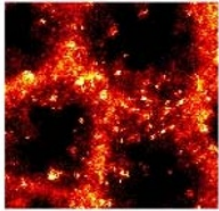

Control

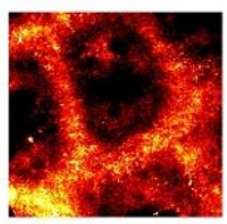

Irradiated

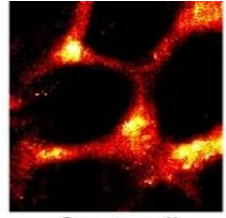

Captopril

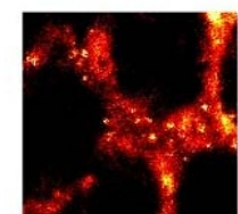

Irradiated + Captopril

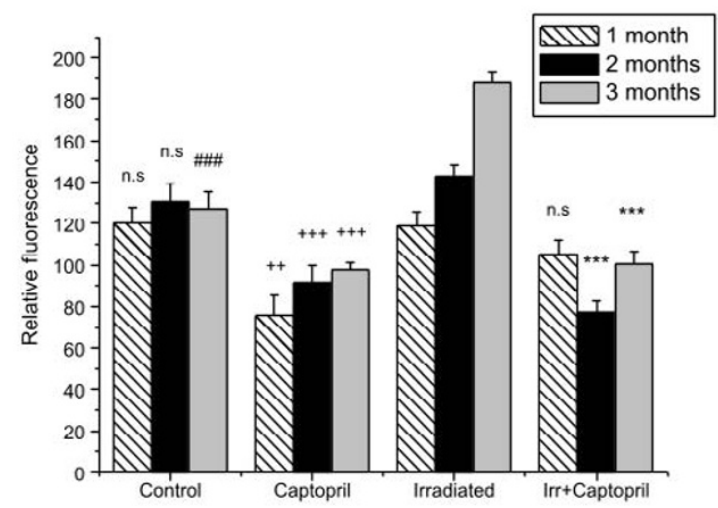

Figure 6 Collagen type IV in the pericryptal space of rat descending colon after irradiation (8Gy) and captopril treatment at 1, 2 and 3 months. Data shown as mean fluorescence ( $n=3$ animals). Data analysed by ANOVA and Tukey-Kramer multiple comparison tests. All comparisons are to irradiated group; \#- Control vs Irradiated, +- Captopril vs Irradiated, *- Irradiated + Captopril vs Irradiated.

\section{Figure 6}

these organs. It has been shown that the formation of scarlike epiretinal membranes is a result of TGF- $\beta$ induced myofibroblast activation and may be related to the end stage of diabetic retinopathy [51].

The density of TGF- $\beta$ type I receptors is significantly increased in the descending colon of LS dieted rats specifically on myofibroblasts; indicating that it is TGF- $\beta$ in conjunction with AT II that provides the trophic stimulus for activation and subsequent collagen production. However, there are also significant levels of TGF- $\beta 1$ receptors in the caecum, which are increased under LS diet. The lack of a pericryptal sheath in the caecum as shown by the lack of OB-cadherin and smooth muscle actin and the absence of collagen deposition and ACE production would suggest that TGF- $\beta 1$ receptors are not localised to myofibroblasts at this site. The caecum has a much more extensive capillary network than the descending colon [2] as shown by the presence of the vascular endothelial adhesion mole- cule PECAM-1. In the caecum, with both high and LS diets, PECAM- 1 is found co-localised with TGF- $\beta 1$ receptors, suggesting that these receptors are up-regulated on capillaries $[48,52]$ rather than myofibroblasts at this site.

The smooth muscle actin antigen is present in the pericryptal sheath and is used as a marker of myofibroblasts. It is increased in the pericryptal sheath cells of descending colon in rats subjected to LS diet and present to a much lesser extent in HS diet. OB-cadherin is a cadherin mainly found in mesenchymal tissue [53-55] although a small presence is found in descending colonic and caecal epithelia. This may be due to some cross reactivity with other cadherins raising the background levels in caecum and descending colonic luminal epithelium.

\section{Increase in ACE, and Collagen IV after LS diet}

It is known that activation of myofibroblasts by AT II and TGF- $\beta$ results in collagen synthesis and enhancement of ACE activity at sites of collagen production $[27,28]$. Hence an increase in collagen and ACE is to be expected at sites of myofibroblast activation. This prediction is corroborated by our findings that both ACE and collagen are significantly increased in the pericryptal sheath surrounding the descending colon of LS dieted rats and virtually absent from caecum in rats with either high or LS diet

Thus the increases in collagen IV, a product of myofibroblasts; myofibroblast specific adhesion molecules (OB cadherin) and smooth muscle actin a cytoskeletal element associated mainly with myofibroblasts, as previously shown [1], are all consistent with a specific growth stimulus to the pericryptal sheath cells.

\section{Absence of myofibroblast activation in caecal mucosa.}

An important factor in inferring the causal relationship between development of the barrier function of the pericryptal sheath and the absorptive function of descending colonic crypts is the total absence of this relationship in the caecal crypts of the same animals.

The caecum, unlike the descending colon is unable to absorb fluid from a high hydraulic resistance within its lumen. This has been related to the absence of any significant pericryptal barrier, which is an essential component of the crypts capacity to generate a hypertonic absorbate $[1,2]$. We have also shown recently that caecal permeability to FITC dextran is much higher than the descending colon providing further evidence for a lack of barrier capacity in the caecal pericryptal space [5]. We showed previously that smooth muscle actin, F-actin, Ecadherin or $\beta$-catenin are virtually absent from the caecal pericryptal sheath. In the present study we show that the myofibroblast-specific adhesion molecule OB-cadherin (also named cadherin 11) [53-55] is not up-regulated in 
caecal crypts by LS diet. Nor are any changes in the amounts of collagen IV, ACE, or AT 1 receptor observed.

Despite the presence of AT1 receptors in caecum, no clear increase in AT1 receptors is found with LS diet in caecum. This may suggest that other growth factors are required before myofibroblastic and epithelial growth can be stimulated. Alternatively, there may be factors that specifically repress myofibroblastic activation within the caecum.

\section{Long term response of pericryptal sheath after radiation} Myofibroblast cells have been implicated in fibrotic lesions in a number of different situations, including radiotherapy of the abdomino-pelvic region [34]. In the lung, it has been shown that radiation causes proliferation of these cells in conjunction with increased collagen synthesis $[43,44]$. The increases in smooth muscle actin, particularly at two and three months (Figure 5) indicate that there is proliferation of myofibroblasts in the pericryptal sheath in descending colon. A number of different cytokines have been implicated in intestinal fibrosis and one of the most important of these is TGF- $\beta$. Increased levels of TGF- $\beta$ have been clearly demonstrated in the small intestine following both single and fractionated radiation exposure suggesting a role of this cytokine in the pathogenesis of both primary and consequential radiation enteropathy [56]. The present results show that the TGF- $\beta$ type 1 receptor is up-regulated at one to two months, (Figure 4). This strongly suggests increased levels of TGF- $\beta$ in the colon, as has been shown in other fibrotic lesions $[35,44]$. Increased amounts of the TGF- $\beta$ receptor localized in the pericryptal sheath suggest that it is exerting local effects on the myofibroblast cells. The increase in smooth muscle actin, which occurs slightly after TGF- $\beta$ receptor upregulation, implies that TGF- $\beta$ induces myofibroblast differentiation and proliferation. TGF- $\beta$-induced morphological and functional differentiation of myofibroblast cells resulting in increased smooth muscle actin and stress fibres have previously been shown in cell culture [57].

The results also show that collagen type IV is increased at three months post-irradiation, confirming previous studies showing marked increases in collagen at 3-6 months post-irradiation [58]. The increase in collagen is preceded by the increases in TGF- $\beta$ receptors and smooth muscle actin suggesting that one of the main stimuli driving the increase in collagen is TGF- $\beta$ probably acting on the myofibroblasts. It has been also been shown that neutralization of endogenous TGF- $\beta$ inhibits increases colonic in collagen [59].

The findings that TGF- $\beta$ receptors, smooth muscle actin and collagen are increased during 1-3 month period postirradiation suggest that one of the major factors in the fi- brotic process is cytokine-mediated activation of the myofibroblasts. Fibrosis may be initiated by AT-ll-induced changes, as is evident from the fact that the ACEI, Captopril inhibits this process. This indicates that AT-II induced events are an integral part of the fibrotic process.

Studies on lung fibrosis induced after radiation, suggests that the anti-fibrotic effect of ACEI are directly related to inhibition of AT-II synthesis, rather than other collateral pharmacological properties, such as anti-oxidation or protease inhibition [44].

An interesting aspect of the results is the fact that both in unirradiated and irradiated tissues Captopril treatment causes a reduction in expression of pericryptal sheath structures with respect to untreated control tissues. This suggests that colonic myofibroblasts, require constant stimulation by cytokines to maintain their steady state level of expression and that suppression of this stimulus leads to down-regulation of myofibroblast synthesized proteins e.g. collagen and ACE.

Both altered dietary $\mathrm{Na}^{+}$and whole body irradiation result in marked changes in descending colon pericryptal myofibroblasts. In LS dieted rats there is evidence of TGF$\beta$ and Angiotensin II mediated myofibroblast activation resulting in extracellular matrix deposition. The same process of cytokine mediated myofibroblast activation also occurs after radiation, resulting in the increased amounts of collagen, characteristic of post-irradiation fibrotic lesions. Pharmacological intervention with the ACE inhibitor Captopril results in the inhibition of these changes. This finding provides further evidence for an important modulatory role of Angiotensin II in colonic function and may be of use in the treatment of colonic fibrosis post-irradiation.

TGF- $\beta$ mediated changes to myofibroblasts have been shown in other tissues and in culture but have additional importance in the descending colon due to the role of the pericryptal sheath in fluid absorption.

\section{Abbreviations}

AT1 Angiotensin II type 1 receptor;

ACE Angiotensin converting enzyme;

TGF- $\beta$ R1 Transforming growth factor $\beta$ type I receptor

\section{Competing interests}

None declared.

\section{Acknowledgements}

The authors wish to thank Dr Barbara Whitehouse, Physiology Group, School of Biomedical Sciences, King's College London for advice regarding high and LS diets and Mr Ray Andrews for his expert help in maintaining and 
controlling the animal diets. The authors also wish to thank Dr F Lebrun and B Ksas for help with the Captopril experiments.

We are grateful to the Wellcome Trust for financial support and to Electricité de France.

\section{References}

I. Naftalin RJ, Pedley KC: Regional crypt function in rat large intestine in relation to fluid absorption and growth of the pericryptal sheath. J. Physiol. (Lond) I999, 5 I 4:2 I I-227

2. Naftalin RJ, Zammit PS, Pedley KC: Regional differences in rat large intestinal crypt function in relation to dehydrating capacity in vivo. J. Physiol. (Lond) 1999, 5 I 4:201-210

3. Desmouliere A, Gabbiani G: Modulation of fibroblastic cytoskeletal features during pathological situations: the role of extracellular matrix and cytokines. Cell Motil. Cytoskeleton 1994, 29:195-203

4. Danjo Y, Gipson IK: Actin 'purse string' filaments are anchored by E-cadherin-mediated adherens junctions at the leading edge of the epithelial wound, providing co-ordinated cell movement. J. Cell. Sci. I 998, I I I:3323-3332

5. Thiagarajah JR, Pedley KC, Naftalin RJ: Evidence of amiloride sensitive fluid absorption in rat descending colonic crypts from confocal microscopic studies of fluorescence recovery after photobleaching. J. Physiol-London 200I, 536:54 I-553

6. Thiagarajah JR, Jayaraman S, Naftalin RJ, Verkman AS: In vivo fluorescence measurement of $\mathrm{Na}^{+}$concentration in the pericryptal space of mouse descending colon: direct evidence for accumulation of a hypertonic absorbate. Am. J. Physiol-Cell. 200I, 281:C1898-C1903

7. Edmonds CJ, Marriot JC: The effect of aldosterone and adrenalectomy on the electrical potential difference of rat colon and on the transport of sodium, potassium, chloride and bicarbonate. I Endocrin 1967, 39:517-53 I

8. Clauss W: Segmental action of aldosterone on water and electrolyte transport across rabbit colon in vivo. Comp Biochem Physiol 1988, 58 I:873-877

9. Sellin JH, Desoigne R: Rabbit proximal colon - a distinct transport epithelium. Am J Physiol 1984, 246:G603-610

10. Asher C, Wald H, Rossier B, Garty H: Aldosterone induced increase in the abundance of $\mathrm{Na}^{+}$channel subunits. Am J Physiol |996, 27 I:C605-C6 |

II. Palmer LG, Antoninian L, Silver G, Frindt G: Regulation of $\mathbf{N a}^{+}$ channels of the rat cortical collect tubule by aldosterone. J Gen Physiol 1993, 102:25-42

12. Sellin JH, Oyarzabal H, Cragoe EJ: Electrogenic sodium absorption in rabbit caecum in vitro. I Clin Invest 1988, 8 I: I275- I 283

13. Fromm M, Hegel $U$ : Net ion fluxes and zero flux limiting concentrations in rat upper colon and rectum during anesthesiainduced aldosterone liberation. Pflug Archiv 1987, 408:185-193

14. Turnamian SG, Binder HJ: Aldosterone and glucocorticoid receptor-specific agonists regulate ion transport in rat proximal colon. Am J Physiol I990, 258:G492-498

15. Wang KS, Ma T, Filiz F, et al: Colon water transport in transgenic mice lacking aquaporin-4 water channels. Am J Physiol 2000 , 279:G463-70

16. Sandle GI: Salt and water absorption in the human colon: a modern appraisal. Out 1998, 43:294-299

17. Escoubet B, Coureau C, Bonvalet JP, Farman N: Noncoordinated regulation of epithelial $\mathrm{Na}^{+}$channel and $\mathrm{Na}^{+}$pump subunit mRNAs in kidney and colon by aldosterone. Am. J. Physiol. 1997, 272:Cl482-CI49|

18. Pradervand S, Barker PM, Wang Q, Ernst SA, Beermann F, Grubb BR, Burnier M, Schmidt A, Bindels RJM, Gatzy JT, Rossier BC, Hummler $E$ : Salt restriction induces pseudohypoaldosteronism type I in mice expressing low levels of the $\beta$-subunit of the amiloride-sensitive epithelial sodium channel. Natl. Acad. Sci. USA 1999, 96:1732-1737

19. Berger S, Bleich M, Schmid W, Cole TJ, Peters J, Watanabe H, Kriz W, Warth R, Greger R, Schutz G: Mineralocorticoid receptor knockout mice: Pathophysiology of $\mathrm{Na}^{+}$metabolism. Proc. Natl Acad Sci. USA 1998, 95:9424-9429

20. Epple HJ, Amasheh S, Mankertz J, et al: Early aldosterone effect in distal colon by transcriptional regulation of ENaC subunits. Am. J. Physiol 2000, 278:G718-G724
2I. Weber KT, Brilla CG: Pathological hypertrophy and cardiac interstitium: fibrosis and renin angiotensin-aldosterone system. Circulation 1991, 83: 1849-1865

22. Weber KT, Sun Y, Katwa LC: Myofibroblasts and local angiotensin II in rat cardiac tissue repair. Int. J. Biochem. Cell. Biol. | 997, 29:3 |-42

23. Katwa LC, Sun Y, Campbell SE, Tyagi SC, Dhalla AK, Kandala JC, Weber KT: Pouch tissue and angiotensin peptide generation. Mol Cell Cardiol I 998, 30: | 40 I- |423

24. Oemar BS, Loscher TF: Connective tissue growth factor: friend or foe. Arterioscl Thromb Vasc Biol 1997, I7: I 483-I489

25. Laiho M, Weis MB, Massague J: Concomitant loss of transforming growth factor (TGF)-beta receptor types II and I in TGFbeta-resistant cell mutants implicates both receptor types in signal transduction. J Biol Chem 1990, 265: I85 I8-18524

26. Boyd FT, Massague J: Transforming growth factor-beta inhibition of epithelial cell proliferation linked to the expression of a 53-kDa membrane receptor. J Biol Chem 1989, 264:2272-2278

27. Campbell SE, Katwa LC: Angiotensin II stimulated expression of transforming growth factor-betal in cardiac fibroblasts and myofibroblasts. J Mol Cell Cardiol 1987, 29:1947-587

28. Cohen EP, Molteni A, Hill P: Captopril preserves function and ultrastructure in experimental radiation nephropathy. Lab Invest 1996, 75:349-360

29. Bentzen SM, Overgaard J, Thames HD, et al: Clinical radiobiology of malignant melanoma. Radiother. Oncol. 1989, I6:169-182

30. McDonald S, Rubin P, Phillips TL, et al: Injury to the lung from cancer therapy: clinical syndromes, measurable endpoints, and potential scoring systems. Int]. Radiat. Oncol. Biol. Phys. 1995, 3 I : I | 87- I 203

3I. Fajardo LF, Stewart JR: Pathogenesis of radiation-induced myocardial fibrosis. Lab Invest 1997, 329:244-257

32. Geraci JP, Mariano MS: Radiation hepatology of the rat: parenchymal and nonparenchymal cell injury. Radiat. Res. 1993, 136:205-213

33. Gabbiani G: Modulation of fibroblastic cytoskeletal features during wound healing and fibrosis. Pathol. Res. Pract. 1994, 190:85 I-853

34. Powell DW, Mifflin RC, Valentich JD: Myofibroblasts. II. Intestinal subepithelial myofibroblasts. Am. J. Physiol I999, 277:C I83-C20 I

35. Moulin V: Growth factors in skin wound healing. Eur. J. Cell Biol. 1995, 68: I-7

36. Trojanowska M, LeRoy EC, Eckes B, et al: Pathogenesis of fibrosis: type I collagen and the skin. J. Mol. Med. 1998, 76:266-274

37. Clouthier DE, Comerford SA, Hammer RE: Hepatic fibrosis, glomerulosclerosis, and a lipodystrophy-like syndrome in PEPCK-TGF-betal transgenic mice. J. Clin. Invest 1997, 100:2697-27|3

38. Wang J, Zheng H, Sung CC, Richter KK, Hauer-Jensen M: Cellular sources of transforming growth factor-beta isoforms in early and chronic radiation enteropathy. Am J. Pathol. I998, I 53:I53 I40

39. Graham MF, Willey A, Adams ]: Corticosteroids increase procollagen gene expression, synthesis, and secretion by human intestinal smooth muscle cells. Oastroenterology 1995, 109:|454|46|

40. Tan LB, Brilla C, Weber KT: Prevention of structural changes in the heart in hypertension by angiotensin converting enzyme inhibition. J. Hypertens. Suppl 1992, I0:S3 I-S34

4I. Ward WF, Molteni A, Ts'ao CH: Radiation-induced endothelial dysfunction and fibrosis in rat lung: modification by the angiotensin converting enzyme inhibitor CL2428 I7. Radiat. Res. | 989, I | 7:342-350

42. Yarom R, Harper IS, Wynchank S: Effect of Captopril on changes in rats' hearts induced by long-term irradiation. Radiat. Res. 1993, 1 33:187-197

43. Nguyen L, Ward WF, Ts'ao $\mathrm{CH}$ : Captopril inhibits proliferation of human lung fibroblasts in culture: a potential antifibrotic mechanism. Proc. Soc. Exp. Biol. Med. 1994, 205:80-84

44. Molteni A, Moulder JE, Cohen EF: Control of radiation-induced pneumopathy and lung fibrosis by angiotensin-converting enzyme inhibitors and an angiotensin II type I receptor blocker. Int. J. Radiat. Biol. 2000, 76:523-532

45. DI Fattah, Whitehouse BJ, Vinson GP: Biosynthesis of aldosterone from I8-hydroxylated precursors in rat adrenal tissue in vitro. J. Endocrin. 1977, 75:187-195 
46. Abayasekara DRE, Onyezili NI, Whitehouse BJ, et al: Effects of chronic corticotropin treatment on aldosterone metabolism in the rat. J. Endocrin. 1993, 137:445-455

47. Skinner SA, O'Brien PE: The microvascular structure of the normal colon in rats and humans. J. Surg. Res. 1996, 61:2:482-90

48. Paris F, Fuks K, Kang A, Capodieci P, Juan G, Ehleiter D, HaimovitzFriedman A, Cordon-Cardo C, Kolesnick R: Endothelial Apoptosis as the Primary lesion Initiating Intestinal Radiation Damage in Mice. Science. 200I293-297

49. Moulder JE, Fish BL: Angiotensin converting enzyme inhibitor Captopril does not prevent acute radiation damage in the rat. Radiat. Oncol. Investis. 1997, 5:50-53

50. Thiagarajah JR, Gourmelon P, Griffiths NM, et al: Radiation induced cytochrome $\mathrm{c}$ release causes loss of rat colonic fluid absorption by damage to crypts and pericryptal myofibroblasts. Out 2000, 47:675-684

5I. Bochaton-Piallat ML, Kapetanios AD, Donati G, et al: TGF-beta I, TGF-beta receptor II and ED-A fibronectin expression in myofibroblast of vitreoretinopathy. Invest. Ophthalmol. Vis. Sci. 2000, $41: 2336-42$

52. DeLisser HM, Christofidou-Solomidou M, Strieter RM, et al: Involvement of endothelial PECAM-I/CD3I in angiogenesis. Am. J. Pathol. 1997, I 5 I:367|-7

53. Simonneau L, Kitagawa M, Suzuki S, Thierry JP: Cadherin II expression marks the mesenchymal phenotype: towards new functions for cadherins? Cell. Adhes. Comm. 1995, 3: I I5-132

54. Hoffmann I, Balling R: Cloning and expression analysis of a novel mesodermally expressed cadherin. Develop Biol 1995, 169:337346

55. Kimura $\mathrm{Y}$, Matsunami $\mathrm{H}$, Inoue $\mathrm{T}$, et al: Cadherin-I I expressed in association with mesenchymal morphogenesis in the head, somite, and limb bud of early mouse embryos. Develop. Biol. 1995, 169:347-358

56. Richter KK, Landberg CW, Sung CC, Hauer-Jensen M: Increased transforming growth factor $\beta$ (TGF- $\beta$ ) immunoreactivity is independently associated with chronic injury in both consequential and primary radiation enteropathy. Int. J. Radiat. Oncol. Biol. Phys. 1997, 39:187-195

57. Vaughan MB, Howard EW, Tomasek J]: Transforming growth factor-betal promotes the morphological and functional differentiation of the myofibroblast. Exp. Cell Res. 2000, 257:180-189

58. Skwarchuk MW, Travis EL: Changes in histology and fibrogenic cytokines in irradiated colorectum of two murine strains. IntJ. Radiat. Oncol. Biol. Phys. 1998, 42:169-178

59. van Tol EA, Holt L, Li FL, et al: Bacterial cell wall polymers promote intestinal fibrosis by direct stimulation of myofibroblasts. Am. J. Physiol 1999, 277:G245-G255

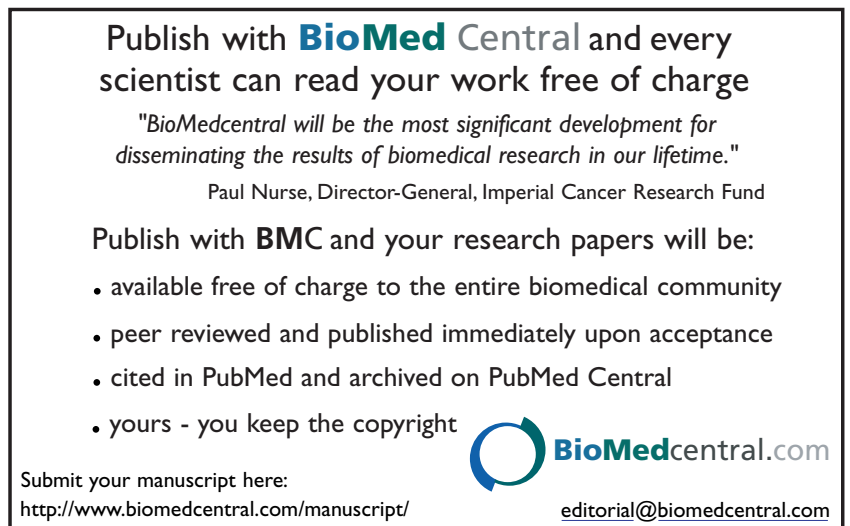

